\title{
Uma virada vital-praxiológica na formação indisciplinar de educadores
}

\author{
Antonio Miguel ${ }^{1}$ \\ Universidade Estadual de Campinas - UNICAMP \\ Carolina Tamayo ${ }^{2}$ \\ Universidade Federal de Minas Gerais - UFMG \\ Elizabeth Gomes Souza ${ }^{3}$ \\ Universidade Federal do Pará - UFPA \\ Alexandrina Monteiro ${ }^{4}$ \\ Universidade Estadual de Campinas - UNICAMP
}

\begin{abstract}
RESUMO
Neste artigo, com base nos trabalhos de Wittgenstein, apresentamos uma imagem de matemáticaS que permite desconstruir discursos colonialistas que as veem como um saber unitário, universal, lógico-formal, abstrato e neutro a ditar normas deterministas para o mundo vital-praxiológico, bem como consideramos outro modo de se fazer as matemáticaS participarem de uma formação indisciplinar de educadores orientada por uma ética-política decolonial que promova a diversidade de formas de vida e a convivência colaborativa e democrática entre os seres naturais que as constituem. Como exemplo disso, descrevemos a prática cultural amazônica de garimpagem de ouro - que, em seus aspectos regrados orientados por propósitos normativos comunitários, poderia ser vista como uma matemática -, problematizando-a em seus efeitos e afetos ambientais, políticos,
\end{abstract}

Submetido em: 08/01/2022

Aceito em: 14/02/2022

Publicado em: 08/03/2022

${ }^{1}$ Licenciado em Matemática pela Pontifícia Universidade Católica de Campinas (PUCCAMP), mestre, doutor e livredocente em Educação pela Universidade Estadual de Campinas (UNICAMP), docente junto ao Departamento de Ensino e Práticas Culturais da Faculdade de Educação da Universidade Estadual de Campinas (UNICAMP). Participa do grupo de pesquisa Phala. ORCID: http://orcid.org/0000-0001-7156-8291 E-mail: miguel37.unicamp@gmail.com

${ }^{2}$ Doutora em Educação pela Universidade Estadual de Campinas (UNICAMP). Professora da Faculdade de Educação da Universidade Federal de Minas Gerais (UFMG). Coordenadora para América do Sul da Red Internacional de Etnomatemática. Integrante do grupo de pesquisa inSURgir (UFMG) e Grupo de Pesquisa Phala. Algumas reflexões colocadas neste artigo são produto do projeto "(M)matemáticas: diálogos de saberes na formação e na pesquisa de/com professores indígenas" da UFMG financiado pela Pró-reitora de Pesquisa mediante o edital no. 07/2020. ORCID: https://orcid.org/0000-0002-8478-7845. E-mail: carolinatamayo@ufmg.br

${ }^{3}$ Licenciada em Matemática pela Universidade Federal do Pará (UFPA). Doutora em Ensino, Filosofia e História das Ciências pela Universidade Federal da Bahia e Universidade Estadual de Feira de Santana. Docente do Instituto de Educação Matemática e Científica- Universidade Federal do Pará. Vice-líder do Grupo de Estudos e Pesquisas em Modelagem Matemática-UFPA. Coordenadora do Projeto de Pesquisa- UFPA- Práticas Socioculturais, Modelagem Matemática e Decolonialidade na Amazônia. Docente do Programa de Pós-Graduação em Educação em Ciências e Matemáticas. ORCID: https://orcid.org/0000-0001-7119-0348 E-mail: elizabethgs@ufpa.br

${ }^{4}$ Licenciada em Matemática pela Pontifícia Universidade Católica de Campinas, Mestre em Educação Matemática pela Universidade Estadual Paulista Júlio de Mesquita Filho, doutora em Educação e pós-doutora em Filosofia da Educação pela Universidade Estadual de Campinas. Docente e pesquisadora junto ao Departamento de Ensino e Práticas Culturais e do Programa de Pós-Graduação em Educação da Faculdade de Educação da Universidade Estadual de Campinas. Participa do grupo de pesquisa Phala. ORCID: https://orcid.org/0000-0002-5803-1358 E-mail: alemath@unicamp.br

Revista de Educação Matemática (REMat), São Paulo (SP), v. 19, Edição Especial, pp. 1-22, e022004, 2022,

eISSN: 2526-9062

DOI: $10.37001 /$ remat25269062v19id725

Sociedade Brasileira de Educação Matemática Regional São Paulo (SBEM-SP) 
econômicos, sociais, sanitários, jurídicos, dentre outros.

Palavras-chave: Formação indisciplinar de educadores; Virada vital-praxiológica; MatemáticaS; Decolonialidade; Desconstrução.

\title{
A vital-praxiological turn in the undisciplined training of educators
}

\begin{abstract}
In this article, based on the works of Wittgenstein, we present a picture of mathematicS that allows deconstructing colonialist discourses that see them as a unitary, universal, logical-formal, abstract and neutral knowledge, dictating deterministic norms for the vital-praxiological world, as well as we consider another way to make mathematicS participate in an undisciplined educators formation guided by a decolonial political-ethics that promotes the diversity of forms of life and the collaborative and democratic coexistence between the natural beings that constitute them. As an example of this, we describe the Amazonian cultural practice of gold mining - which, in its ruled aspects guided by normative community purposes, could be seen as a mathematics -, problematizing it in its environmental, political, economic, social, sanitary and legal effects and affects.
\end{abstract}

Keywords: Indisciplinary training of educators; Vital-praxiological turn; MathematicS; Decoloniality; Deconstruction.

\section{Un giro vital-praxiológico en la formación indisciplinar de educadores}

\section{RESUMEN}

En este artículo, basado en los trabajos de Wittgenstein, presentamos una imagen de matemáticaS que permite deconstruir los discursos colonialistas que las ven como un conocimiento unitario, universal, lógico-formal, abstracto y neutral, dictando normas deterministas para el mundo vitalpraxiológico, así como también consideramos otra forma de hacer partícipe a las matemáticaS de una formación indisciplinar de educadores guiados por una ética político-decolonial que promueva la diversidad de formas de vida y la convivencia colaborativa y democrática entre los seres naturales que las constituyen. Como ejemplo de esto, describimos la práctica cultural amazónica de la minería aurífera - que, en sus aspectos regulados guiados por fines normativos comunitarios, podría verse como una matemática -, problematizándola en sus efectos y afectos ambientales, políticos, económicos, sociales, sanitarios, legales, entre otros.

Palabras clave: Formación indisciplinar de educadores; Giro vital-praxiológico; MatemáticaS; Decolonialidad; Deconstrucción.

\section{UMA VIRADA VITAL-PRAXIOLÓGICA NA FORMAÇÃO INDISCIPLINAR DE EDUCADORES}

Embora esteja hoje bem estabelecida, na comunidade de educadores matemáticos, a imagem que afirma a existência de diferentes matemáticas, ainda há muitas polêmicas e divergências sobre os argumentos que poderiam sustentá-la. Entretanto, os argumentos que 
se costumam apresentar em defesa dessa diversidade nem sempre abalam a imagem unitária, universal, abstrata, essencialista e lógico-formal-fundamentalista da Matemática que ainda impera, sobretudo, no interior de comunidades acadêmicas de praticantes da matemática.

Um exemplo de defesa dessa imagem nos é apresentado pelo matemático Marcelo Viana $^{5}$ - atual diretor do Instituto de Matemática Pura e Aplicada (IMPA) - em uma entrevista por ele concedida ao jornal paranaense "A gazeta do Povo". Com base na problematização dos principais argumentos por ele manifestados nessa entrevista, o propósito deste artigo é o de argumentar pela diversidade de matemáticaS que nos permita considerá-las em um modo decolonial possível de formação indisciplinar de educadores.

O desejo de Vianna de ver uma essência universalista, formal e abstrata nas matemáticaS efetivamente praticadas no plural não passa de um desejo colonizador de tornar indistintas - assimilando-as à sua "matemática no singular" - todas as demais matemáticaS praticadas em diferentes campos de atividade humana. Ele diz isso assim:

\begin{abstract}
A matemática, como qualquer atividade humana, não surge no vazio: ela é utilizada dentro de um contexto. Acho muito importante estudar as formas de aplicação da matemática ao longo da história. Mas uma confusão que me parece frequente é a de achar que isso é matemática; ou que fazer esse tipo de estudo faz parte da matemática em si - e isso é uma falácia. O conteúdo da matemática é independente (VIANA, 2021, itálicos nossos).
\end{abstract}

Como se nota, para Viana, não faz sequer sentido problematizar a possibilidade de se pensar em outras matemáticaS, uma vez que as diferentes matemáticas que conseguimos e podemos legitimamente ver nas práticas de outras comunidades não passariam, para ele, de meros "usos" ou "aplicações", em diferentes "contextos culturais", de uma mesma matemática única, universal e verdadeira.

\footnotetext{
${ }^{5}$ Trata-se da matéria intitulada "Não faz sentido falar em desconstrução da matemática", publicada no jornal "Gazeta do Povo" em 17/03/2021. Ao problematizarmos os argumentos apresentados por Vianna, não intencionamos personificar o alvo da nossa crítica, mas dirigi-la a um persistente discurso filosófico-idealista hegemônico acerca da matemática que mobiliza argumentos semelhantes, tais como, por exemplo: o intitulado "Educação matemática 'crítica' e o fracasso da educação matemática", de Jairo da Silva, publicado no mesmo jornal, em 05/03/2021; as entrevistas intituladas "Quando a matemática deixou de ser o bicho papão" (24/07/2019) e "Desempenho da pesquisa em matemática não se reflete no ensino da disciplina", ambas da matemática Suely Druck. Estas matérias podem ser respectivamente acessadas nos links: (https://www.gazetadopovo.com.br/ideias/marcelo-viana-nao-faz-sentido-falar-em-desconstrucao-damatematica/?\#success=true); (https://www.gazetadopovo.com.br/opiniao/artigos/educacao-matematica-critica-e-ofracasso-do-ensino-de-matematica/); (https://www.nosso.jor.br/quando-a-matematica-deixou-de-ser-o-bicho-papao/); Jornal da UNICAMP de 14/02/2005).
}

Revista de Educação Matemática (REMat), São Paulo (SP), v. 19, Edição Especial, pp. 1-22, e022004, 2022, eISSN: 2526-9062

DOI: $10.37001 /$ remat25269062v19id725

Sociedade Brasileira de Educação Matemática - Regional São Paulo (SBEM-SP) 
Nesse sentido, ele defende e reforça - mesmo que talvez não o pretenda - o próprio ponto de vista colonizador, sempre desejoso de "limpar" a "matemática única" de qualquer "impureza" praxiológica, empírico-visual, material ou concreta com que outras comunidades de prática a maculam ou poderiam vir a maculá-la no futuro.

É esta imagem de matemática única que leva Viana a considerar "a mesma" as matemáticas praticadas pelos antigos artesãos-ceramistas mesopotâmicos, pelos pedramistas das "belíssimas" calçadas portuguesas e pelos ceramistas marajoaras paraenses:

\begin{abstract}
Existe um teorema na matemática segundo o qual existem 24 tipos de simetria; um tipo de padrão que pode ser encontrado em pinturas, na natureza etc. Se você analisar obras de arte escavadas da Mesopotâmia há 5000 anos, vai encontrar cerâmicas que contém esses tipos de simetria. Se você passear em Lisboa, vai perceber que aquelas belíssimas calçadas de pedra portuguesa, usam os mesmos padrões, também presentes nas cerâmicas marajoaras, no Pará. Embora os materiais utilizados e os símbolos representados sejam diversos, a matemática utilizada é exatamente a mesma. Por isso, desconstruir a matemática é uma expressão completamente sem sentido (VIANA, 2021, itálicos nossos).
\end{abstract}

Como se nota, o argumento que o leva a vê-las como "uma mesma matemática", ou mesmo, a identificá-las e reconhecê-las como "aplicações de uma mesma matemática", não é outro senão o de vê-las como "matemáticas isomorfas", como matemáticas que mobilizam concretamente, em tempos e contextos culturais diversos, um mesmo tipo formal puro $e$ abstrato de simetria, entre os 24 tipos de simetria já eternamente previstos por sua matemática profética. Em outras palavras, Viana considera "matemática" apenas o esqueleto formal-estrutural-abstrato-genérico - e, portanto, sem conteúdo empírico-praxiológico, ainda que definidor autoritário, restritivo, apriorístico e determinista de qualquer conteúdo empírico-praxiológico - que, neste caso, se pretende expresso pelo conceito de simetria. Assim, este seu olhar (ideo)lógico nada mais faz senão eliminar colonialmente, até descaracterizar por completo, justamente as idiossincrasias e aspectos concretos, particulares, específicos, funcionais, artísticos, em suma, os aspectos empírico-praxiológicos que caracterizam a diversidade, a singularidade e os coloridos típicos dessas diferentes práticas tecnológico-culturais, dessas diferentes matemáticaS produzidas com base em propósitos comunitários diferenciados que produzem e reproduzem a vida em diferentes formas de vida. 
Neste caso, a estratégia colonizadora acionada por Viana se manifesta pela formalização estrutural que invisibiliza e nega as diferenças ou singularidades de práticas culturais que podem ou não compartilhar certos aspectos semelhantes.

É claro que para argumentar dessa maneira - supostamente por ele considerada "científica" -, Viana teria que admitir também, por extensão, aquilo que ele não ousa explicitar em seu argumento, qual seja, a crença metafísica de que antes mesmo da constituição de uma comunidade de matemáticos especializados, teria preexistido uma matemática de padrões figurativos considerados geométricos, simétricos, belos e universais que fundamentaria não só os usos dessa suposta matemática unitária pelas comunidades de artesãos que ele cita, como também, todos os usos possíveis e futuros que poderiam vir a ser mobilizados por outras comunidades de artesãos.

Entender a matemática deste modo, isto é, deixar-se dobrar à perspectiva platônica, impede problematizar ou ver algum sentido em propostas e desejos desconstrucionistas e decolonialistas $^{6}$, pois significaria reconhecer que as práticas culturais voltadas a cumprirem propósitos sociais normativos, ou seja, a atenderem de forma regrada as demandas das diferentes formas de vida, teriam sido e continuam sendo realizadas nos mais diferentes campos de atividade humana, desde antes de "Euclides", desde antes de Aristóteles, desde antes de Platão, desde antes de Pitágoras, desde antes dos gregos, desde antes dos mesopotâmicos... até os dias de hoje, independentemente de tais práticas regradas serem denominadas "matemáticaS", reconhecidas ou não como "matemáticaS".

No entanto, se Viana consegue ver a "sua" matemática num artesanato mesopotâmico que reproduz um padrão simétrico, é simplesmente porque ele ilegitimamente a vê como tendo sido anteriormente projetada pelo "deus-natureza" ou pelo Demiurgo platônico nas supostas formas "geometricamente corretas" dos astros e nos supostos "padrões geométricos simétricos" de certos seres minerais, vegetais ou animais. Não lhe seria, portanto, difícil ver matemática na prática de se fazer pães de forma espiralada, ao modo egípcio antigo, mas tão

\footnotetext{
${ }^{6}$ Sobre as aproximações e afastamentos entre a opção decolonial, a atitude terapêutica do segundo Wittgenstein e a atitude desconstrucionista de Jacques Derrida, consultar (MIGUEL; TAMAYO, 2020).
} 
somente por ver uma "espiral" como uma forma considerada essencialmente "geométrica" ou "matemática".

Desse modo, o olhar estruturalista-formalista de Viana tenderia a não ver - ou a intencionalmente ocultar, desprezando-os como irrelevantes - a consistência, a textura, o sabor e outras características dos pães de forma espiralada produzidos por uma prática em vigor no antigo Egito, para concentrar-se exclusivamente na forma espiralada abstrata dos pães e a considerar tal prática como matemática justamente devido à forma geométrica espiralada dos pães. E por que isso acontece? Acontece, porque Viana só reconhece como matemática, nas práticas e nos artefatos tecnológico-culturais, os objetos/conhecimentos/saberes que a tradição epistemológica investigativa euclidiana estendida e ampliada ao longo do tempo para incorporar em seu domínio novos objetos de investigação -, ainda hoje hegemônica, o ensinou a ver como "objetos matemáticos", isto é, objetos puramente formais, despidos, "descontaminados" e abstraídos, sobretudo das técnicas adequadas e precisas que - combinando e cozendo a mistura de uma quantidade precisa de grãos moídos de cereais com quantidades precisas de outros ingredientes contemplariam inequivocamente o propósito social de se produzir pães com a forma, a consistência, a textura e o sabor desejados. Sob uma perspectiva wittgensteiniana, é justamente tal técnica - isto é, o conjunto de instruções, regras de transformação, receita ou algoritmo - que caracteriza a matemática do fazer pães espiralados à moda egípcia, e não propriamente as formas ou as quantidades de grãos de cereais utilizados, ou ainda, a forma espiralada dos pães produzidos com base nessa técnica. Em outras palavras, se os pães egípcios tivessem a forma de um elefante, Viana, certamente, não veria qualquer matemática neles.

Assim, os olhos de Viana, aprisionados por uma imagem lógico-formal-estruturalista única e exclusivista da matemática, conseguem ver - pelas lentes de um teorema que demonstra, através das definições, axiomas e regras de inferência permissíveis de movimentação no interior de um sistema lógico-dedutivo proposicional - apenas 24 tipos de simetria na natureza. E é com base nesse olhar formalmente fossilizado e colonizado que ele tenta também colonizar e fossilizar as formas vivas da natureza e a natureza viva das formas, bem como as relações técnico-praxiológicas que humanos culturalmente situados 
estabelecem com os demais seres naturais, com o propósito de se contemplar propósitos comunitários compartilhados.

Não pense, veja! $!^{7} \mathrm{O}$ que Viana vê nas urnas funerárias marajoaras da Figura 1? O que ele vê são padrões simétricos idênticos aos das calçadas portuguesas e aos das cerâmicas mesopotâmicas.

Figura 1 - Urna funerária marajoara.

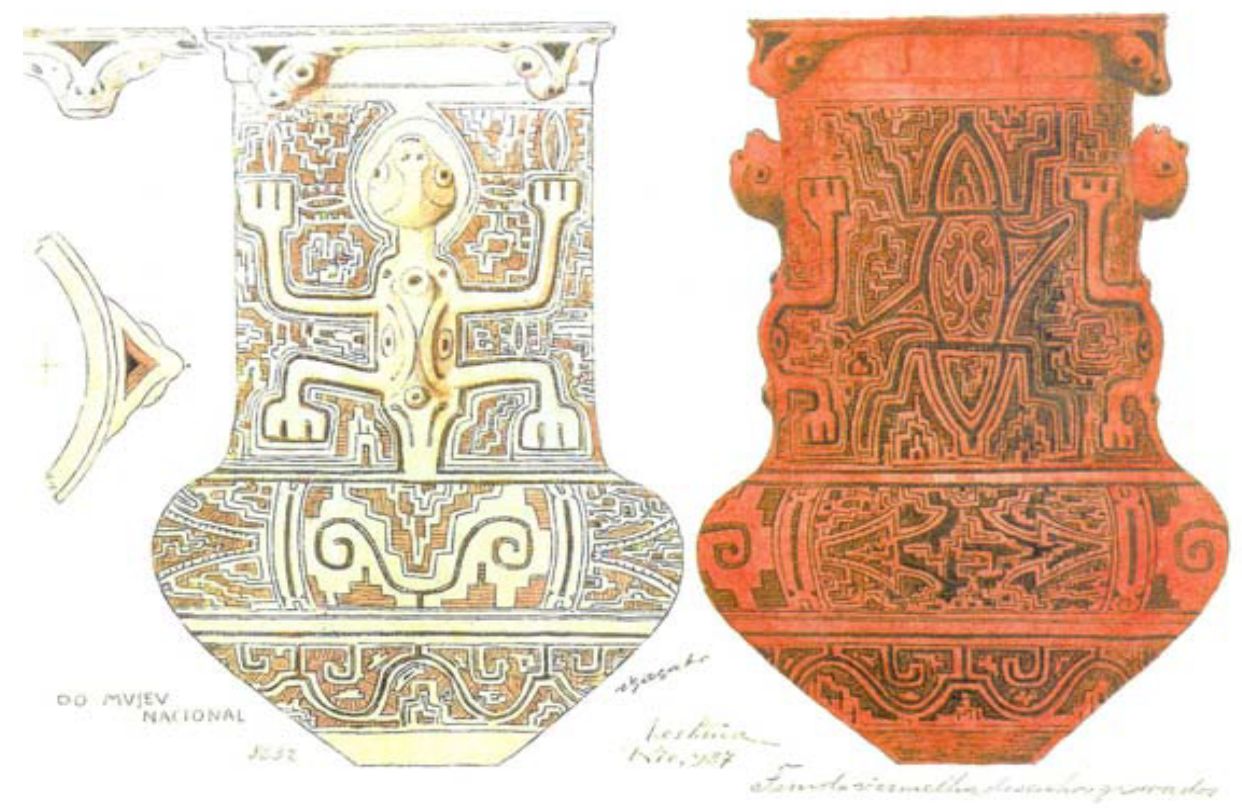

Fonte: Pahl Schaan (2007, p. 108).

A mesma estratégia de redução a que nos referimos anteriormente da prática egípcia de se fazer pães à forma espiralada assumida pelos pães é acionada por Viana para reduzir as práticas de produção das urnas funerárias marajoaras ${ }^{8}$ a certos tipos de padrões simétricos previstos pelo "teorema mágico"9 a que ele se refere, supondo, magicamente, que os artesãos marajoaras teriam antecipado a aplicação da mesma matemática profética que preexistia à sua aplicação e só posteriormente demonstrada por tal teorema.

\footnotetext{
${ }^{7}$ (WITTGENSTEIN, 2017, §66).

${ }^{8}$ Urnas funerárias decoradas com apliques modelados na forma de lagarto e motivos excisos sobre engobo vermelho. Peça do acervo do Museu Nacional, aquarela de Manoel Pastana, acervo do Museu do Forte, Belém. As urnas funerárias da cultura marajoara trazem em geral a figura humana em destaque, mas sempre associada com animais como a cobra, o escorpião, o urubu-rei, o jacaré ou o lagarto, dentre outros. Além disso, a figura humana, quando o sexo pode ser identificado, é predominantemente feminina, o que pode indicar que a matrilinearidade era a maneira organizativa do parentesco. Algumas das figuras das cerâmicas marajoaras possuem significados associados às histórias de povos amazônicos, por exemplo, a cobra grande, a anaconda, em suas diversas formas, desempenha um papel fundamental para a criação do povo Tukano do noroeste amazônico (CHAVES, 2020).

${ }^{9}$ Sobre esse teorema ver artigo: Os matemáticos acharam todas as simetrias. IMPA Notícias, 2019. Matéria que pode ser acessada no seguinte link: (https://impa.br/noticias/os-matematicos-acharam-todas-as-simetrias/).
}

Revista de Educação Matemática (REMat), São Paulo (SP), v. 19, Edição Especial, pp. 1-22, e022004, 2022, eISSN: 2526-9062

DOI: $10.37001 /$ remat25269062v19id725

Sociedade Brasileira de Educação Matemática - Regional São Paulo (SBEM-SP) 
Esta forma fossilmente aprisionada de ver o impede de $v e r^{10}$ a diversidade de artefatos culturais produzidos pelos ceramistas marajoaras - vasos, tangas, urnas funerárias, dentre outros - produzidos com base em práticas e técnicas diversas ${ }^{11}$. Também o impede de ver e significar as imagens estampadas nos artefatos com base nos propósitos sociocomunitários que de fato orientam as suas produções ${ }^{12}$. Assim, ao ver a "mesma matemática" nas cerâmicas marajoaras e nos padrões das calçadas de Lisboa, Viana não consegue ver que só se poderia ver o que ele vê, quando nos obrigamos a significar as palavras "simetria" e "natureza" através de definições analíticas postulacionais, tal como "Euclides" o fez com as palavras e proposições ditas "elementares" de seus Elementos. Assim, onde tenderíamos a ver "matemática" - isto é, nas técnicas de processamento, mistura, excisão, pintura e cozimento do barro para contemplar os propósitos sociais diferenciados de cada artefato cerâmico particular de origem marajoara -, Viana nada vê, e onde ele vê matemática - isto é, nos padrões supostamente simétricos das imagens estampadas no barro -, ele nada mais faz do que projetar indevidamente a imagem lógicoproposicional-formal da matemática, do modo como ele a pratica, sobre as práticas dos artesãos que, para ele, nada têm a ver com tal matemática ${ }^{13}$.

Mas, o exemplo do "teorema mágico" dado por Viana parece desejar ir além desta imagem epistemológica disciplinar-demarcatória que desdobra as formas de vida em mundo da natureza (investigado pelos físicos), mundo das atividades e instituições humanas

\footnotetext{
${ }^{10}$ Para acusar o caráter inflexível desta e outras imagens essencialistas e dogmáticas de matemática, chamamos Wittgenstein (2017, §115): "Uma imagem nos mantinha presos. E dela não podíamos nos livrar, pois ela residia em nossa linguagem que a repetia inexoravelmente". A filosofia wittgensteiniana nos convida a identificar e resistir às imagens fixas e ilusórias que nos enfeitiçam e nos impedem de ver de outros modos os problemas com que nos ocupamos em nossas vidas e em diferentes formas de vida.

${ }^{11}$ Para isso, ver: (https://www.museu-goeldi.br/assuntos/imprensa/downloads/catalogo-ceramica-marajoara.pdf).

12“No decorrer do tempo, as práticas funerárias modificaram-se. Inicialmente, era comum colocarem o indivíduo sentado, com os joelhos flexionados junto ao peito, dentro de uma grande urna e guarnecê-lo com seus pertences pessoais e tigelas com comidas. [...] Depois de algum tempo, os marajoaras passaram a usar um tipo de sepultamento que consistia em colocar apenas os ossos do indivíduo, ou suas cinzas (após o corpo ter sido cremado) no vaso. Esse processo demanda uma série de preparativos e comportamentos rituais" (CHAVES, 2020, p. 56).

${ }^{13}$ A seguinte passagem das Investigações Filosóficas expressa bem tanto o desejo de pureza cristalina dos matemáticos puros quanto o nosso desejo vital-praxiológico de virar pelo avesso o desejo deles: "Reconhecemos que o que chamamos de "proposição", "linguagem", não é a unidade formal que imaginávamos, senão a família de formas mais ou menos aparentadas entre si. [...] O preconceito da pureza cristalina só pode ser afastado quando damos uma virada em toda a nossa consideração. Pode-se dizer: a consideração tem que ser virada, mas ao redor do pivô da nossa real necessidade. [...] A filosofia da lógica não fala de proposições e palavras em sentido diferente do que fazemos na vida cotidiana, quando dizemos "Aqui está uma frase escrita em chinês" ou "Não, isto apenas se parece com caracteres escritos, mas é um ornamento" etc. Falamos do fenomeno espacial e temporal da linguagem; não de um disparate não espacial e não temporal. [Só que pode haver interesse por um fenômeno de modos diferentes]. Mas falamos da linguagem assim, como das peças do jogo de xadrez, quando queremos informar, para elas, as regras do jogo, e não para descrever as propriedades físicas das peças. A pergunta “O que é realmente uma palavra?" é análoga a "O que é uma peça de xadrez"?" (WITTGENSTEIN, 2017, §108, itálicos nossos).
}

Revista de Educação Matemática (REMat), São Paulo (SP), v. 19, Edição Especial, pp. 1-22, e022004, 2022, eISSN: 2526-9062

DOI: $10.37001 /$ remat25269062v19id725

Sociedade Brasileira de Educação Matemática - Regional São Paulo (SBEM-SP) 
(investigado pelos sociólogos e antropólogos) e mundo lógico-formal-abstrato (investigado pelos matemáticos). O seu desejo parece ser também o de hierarquizar deterministicamente esses mundos, subordinando as possibilidades de se descrever humanamente tudo o que se passou, que se passa ou que se passará nesses mundos ao desejo lógico-formal-ideal dos matemáticos. É como se tudo o que tivesse ocorrido, que ocorre ou que venha ainda a ocorrer na natureza ${ }^{14}$ já estivesse predestinado a ocorrer nela; e esse dom profético de previsibilidade é o que teria sido doado por um Deus demiurgo platônico exclusivamente à matemática, ou melhor, à rainha das ciências, predestinada a pairar soberanamente no espaço lógico-formalideal, abstrato e universal, e a apontar o destino humano com o seu cetro deterministicamente infalível.

Em sua entrevista, Viana afirma também que "a tentativa de transformar a matemática em bandeiras ideológicas está por todo lado e precisa ser identificada" (VIANA, 2021). No seu desejo - este, sim, ideológico - de investir contra o que ele institui como "militância pela descolonização da matemática", o seu argumento é sucintamente simples e simplista: "Isso [o teorema de Pitágoras e, por extensão, o "teorema mágico" ou outro qualquer] não é mesopotâmio, não é grego, não é francês, não é africano: isso é matemática!”. E, com este argumento, Viana acaba não apenas mostrando as imagens equivocadas que faz das práticas colonizadoras, das práticas decolonizadoras ${ }^{15} \mathrm{e}$ das práticas desconstrucionistas, como também a sua pueril pretensão de desejar contrapor-se a elas invocando a eterna e atemporal 'transnação platônica', 'origem original' e pura de sua matemática universal, unitária, essencialista e ideal.

Ademais, podemos perguntar: onde 'mora' e quem 'produz' este conhecimento assim tão teológico, tão puro, tão essencialista, tão ideal e tão ideologicamente, eticamente e politicamente neutro que só poderia contaminar-se depois de alguns de seus usos humanos?

\footnotetext{
${ }^{14} \mathrm{Em}$ vez de "na natureza", seria mais apropriado dizer, nas interações praxiológico-vitais que os seres humanos estabelecem com os demais seres naturais.

${ }^{15}$ Ainda que Viana, em sua crítica a certas perspectivas culturais assumidas por educadores matemáticos, as veja como "descolonizadoras" da matemática, situamo-nos na perspectiva de Catherine Walsh (2009) que prefere usar o verbo "decolonizar" em vez de "descolonizar", uma vez que o uso do prefixo "des", no espanhol, remete a significados como “desfazer" ou "reverter", no caso, o colonialismo, isto é, superar um momento colonial para se atingir um não colonial. Já o uso do verbo "decolonizar" pretende marcar uma opção, uma atitude contínua de transgressão à matriz colonial de poder para viabilizar novos horizontes políticos, éticos, econômicos e sociais e visibilizar outros modos de se produzir conhecimento em diferentes formas de vida. O "decolonial" denota um caminho de luta, de desconstrução da universalidade do pensamento e do padrão de poder institucionalizado pelo projeto modernidade/colonialidade.
} 
Para não cair na armadilha de dizer que é a própria comunidade de matemáticos profissionalizados, Viana propõe uma metáfora proveniente do campo da pesquisa biológica, afirmando que tais 'teopropriedades' de pureza "fazem parte do DNA da matemática”. Como podemos perceber, a estratégia ideológica, colonizadora e de cunho religiosamente liberal acionada por este argumento é, em primeiro lugar, separar a matemática (dita pura, unitária, universal, internamente lógica e consistente etc.) das comunidades e das práticas humanas que a produzem e, em seguida, personificá-la como um corpo supra-humano ao qual o deusacaso - também ele supostamente um "deus liberal”, apartidário, isento, neutro, imparcial etc. - teria atribuído um DNA com tais características pueris. É por isso que Viana se vê no direito de afirmar que "o teorema de Pitágoras é agnóstico". Ao que poderíamos responder: não seriam os próprios matemáticos ditos "puros", porém não-ingênuos, pelo menos tão relutantes em ver o quão ingênua, ideológica e militante é a sua utopia de uma matemática que só se torna "boa" ou "má" em seus usos, ainda que o seu DNA tivesse sido originalmente 'programado' pelo ‘deus-acaso' como biologicamente neutro, limpo e puro?

Do nosso ponto de vista, não seria esta matemática dita "pura", "única" e "universal" que emprestaria os seus conceitos, teoremas, métodos e procedimentos para servirem de modelo de resolução de problemas voltados a cumprirem "bons" ou "maus" propósitos. Ao contrário, são os modos como determinados problemas, voltados a cumprirem propósitos sociais normativos, afetam determinadas comunidades de prática que as mobilizam para a invenção de novas matemáticas.

As práticas normativamente orientadas não podem ser vistas como aplicações mecânicas - diretas ou indiretas - de teoremas demonstrados por procedimentos exclusivamente lógico-formais de uma matemática dita "pura", "única", "verdadeira" e "universal". Nem podem retirar desses teoremas as validações de suas técnicas para responderem de forma adequada e satisfatória a problemas emergentes em diferentes formas de vida. O que não significa, por outro lado, que tais teoremas não possam, eventualmente, levantar e responder a novos problemas internos ao próprio campo da matemática acadêmica, ou mesmo, aplicarem-se à investigação de problemas emergentes em outros domínios de conhecimento ou em outros campos de atividade humana ou que, inversamente, problemas emergentes nesses campos não possam ser descritos, considerados e tratados mediante os procedimentos e ferramentas conceituais da matemática acadêmica. 
No Tractatus Logico-Philosophicus (WITTGENSTEIN, 2001), a linguagem é entendida como um espelho lógico da natureza, de modo que todos os sistemas linguísticoformais de signos passam a ser vistos como estruturas isomórficas às disposições lógicoformais de estados de coisas correspondentes presentes no mundo fenomênico. Por tais mundos - o lógico-proposicional e o praxiológico - serem vistos como especularmente isomorfos, tudo o que pudesse ser formalmente demonstrado no mundo logicamente conectado da matemática formal-proposicional demarcava os limites do que poderia ou não ser efetivamente realizado no mundo praxiológico e vice-versa. Quando Alan Turing (TURING, 1936) demonstrou que a matemática proposicional lógico-formal não era completamente decidível e que, portanto, cada um de seus teoremas deveria ser visto como uma resposta a um problema autônomo decidível e independente do sistema, ele rompeu com a visão especular entre mundo lógico e mundo praxiológico, ainda que ele não tivesse se dado conta dessa ruptura e das suas implicações. Porém, esta ruptura já tinha sido realizada de outro modo por Wittgenstein, desde o momento em que ele passou a questionar o desejo dos 'matemáticos-logicistas' de se ver a linguagem ordinária como não-lógica, como imperfeita, como algo que devesse ser depurado de suas 'impurezas mundanas' para que pudesse alicerçar o projeto de construção de uma matemática única, universal e lógicofundamentalista. Foi este tipo de ruptura que permitiu a Wittgenstein passar a ver a matemática não mais como um conjunto supostamente completo e consistente de proposições logicamente encadeadas e hierarquizadas, mas como um conjunto ilimitado de “jogos de linguagem” autônomos, completos e independentes entre si.

Esta quebra de espelho trouxe à cena uma outra imagem da relação entre "linguagem" e "mundo" que não apenas a desconstruía enquanto uma relação de oposição binária, como também desconstruía quer 'o mundo' como um mundo fenomênico unitário e singular, quer 'a linguagem' como unitária e logicamente estruturada. Assim, Wittgenstein passou a falar em jogos de linguagem como praxis, isto é, como práticas linguageiras funcionalmente distintas indissoluvelmente conectadas a práticas culturais que se realizam em diferentes formas de vida e, portanto, como práticas não mais dissociáveis dos saberesfazeres corporais interativamente produzidos por humanos e demais seres naturais em diferentes formas de vida. Se por um lado, esta "quebra de espelho" levou a um 
desatrelamento subordinativo ${ }^{16}$ dos seres e eventos naturais em relação aos nossos jogos de linguagem e aos propósitos e desejos comunitários que os orientam, levou também, por outro lado, ao reconhecimento da existência de condicionamentos e de limites instáveis e mutantes que os seres e eventos naturais imporiam aos nossos jogos de linguagem e aos propósitos e desejos comunitários que os orientam.

Embora autônomos e independentes entre si, os jogos de linguagem - com excessão dos estritamente simbólicos como o são os jogos normativos lógico-formais de linguagem produzidos pela comunidade científica de matemáticos -, só podem ser produzidos em interações mútuas que humanos estabelecem entre si e com os demais seres naturais, de modo que eles não podem mais ser epistemologicamente descritíveis ou avaliáveis em termos da concepção clássica ou de uma outra concepção qualquer de verdade ${ }^{17}$, mas tão somente em termos de suas maiores ou menores adequações para contemplarem os respectivos propósitos comunitários diferenciados que orientam as ações dos jogadores em cada jogo. Nesse sentido, uma é a matemática que se faz e se pratica no mundo lógicosimbólico-formal imaterial, atemporal e não espacial das proposições, mundo este que o Wittgenstein do Tractatus escala, degrau por degrau, para, no final, jogar fora a escada que o auxiliou a subir, simplesmente para desconstrui-lo, mas sem saber como substitui-lo por outro. Outras são as matemáticaS - isto é, os jogos de linguagem orientados por propósitos comunitariamente normativos - que se fazem e se praticam efetivamente no mundo praxiológico-material, temporal e espacial das diferentes formas de vida. É preciso, portanto, diferenciar entre uma efetividade lógico-formal ideal e atemporal e uma efetividade praxiológico-material temporal. A primeira diz respeito às matemáticas que se podem fazer no mundo lógico das proposições. A segunda diz respeito às matemáticaS que podem se inventam e se praticam em diferentes formas de vida. Nem as segundas são aplicações das primeiras e nem as primeiras das segundas. Por exemplo: no mundo lógico-simbólico-formal imaterial, sempre podemos construir um triângulo equilátero, qualquer que seja a medida do seu lado (Primeira Proposição do Livro I de "Euclides"). O que garante a possibilidade da

\footnotetext{
${ }^{16} \mathrm{Ou}$ de qualquer outro tipo: comportamental, determinista, causal, de maior ou menor pureza, de maior ou menor veracidade, de maior ou menor correção, de maior ou menor efetividade praxiológica, de maior ou menor previsibilidade etc.

${ }^{17}$ Vale ressaltar que a "quebra" de espelho não produziu e nem desejou produzir uma outra concepção de verdade, supostamente mais verdadeira do que as demais por ela abandonadas, e nem as substituiu por qualquer outra.
} 
universalidade dessa construção são os primeiros principios (definições, postulados, axiomas e regras de inferência da lógica aristotélica) dos Elementos. Já no mundo praxiológico-material, nem sempre podemos construir efetivamente triângulos, quaisquer que sejam os instrumentos que possamos empregar. Isso porque, triângulos praxiológicos nunca são formas puras atemporais, mas sempre triângulos acessíveis ou inacessíveis direta ou indiretamente construtíveis (triângulos diretamente construtíveis de corda, de madeira, de ferro, de aço, de vidro etc.; ou triângulos indiretamente construtíveis com seus vértices situados nos mares, em montanhas, em pontos subquáticos ou subterrâneos, no espaço sideral etc.).

Assim, os seres humanos não precisaram esperar pelos Elementos de "Euclides" para inventarem técnicas de triangulação e de medição de distâncias acessíveis e inacessíveis para atingirem diferentes propósitos comunitários nos campos de atividade da construção civil, da agricultura, da topografia, da agrimensura, da astronomia, da navegação etc.

A desconstrução de discursos colonizadores relativos à matemática e à educação matemática escolar e universitária nos coloca numa perspectiva decolonial-indisciplinar de formação de educadores escolares que propõe uma virada vital-praxiológica na imagem única e exclusivista de matemática mobilizada por esses discursos. A perspectiva decolonial que defendemos sugere que vejamos as matemáticaS como um conjunto de práticas culturais voltadas a cumprirem propósitos comunitários normativos, dentre as quais também se incluem os jogos normativos simbólico-formais dos matemáticos.

Desse modo, a desconstrução ${ }^{18}$ aqui operada se move pelo convite $^{19}$ ao deslocamento de nosso olhar para os modos como práticas culturais normativas se realizam e se inventam em diferentes formas de vida, tornando-as o alvo da problematização escolar decolonial-indisciplinar e da formação de educadores ${ }^{20}$.

\footnotetext{
${ }^{18}$ Falamos aqui em desconstrução derridiana, a qual se pratica através do duplo gesto da inversão e do deslocamento: "Na inversão, tudo aquilo que foi recalcado, reprimido, abafado ou marginalizado pela filosofia é enfatizado [...] No entanto, o que a desconstrução almeja mesmo é efetuar um deslocamento das oposições para além da dicotomia da metafísica dualista" (HADDOCK-LOBO, 2007, p. 69).

${ }^{19} \mathrm{O}$ estilo ético-estético do filosofar wittgensteiniano co-responsabiliza o leitor pelos desdobramentos gerados pela leitura de sua obra: "Com meu escrito, não quero economizar aos outros o pensar. Mas, se for possível, incitar alguém aos seus próprios pensamentos" (WITTGENSTEIN, 2017, s/n, prefácio).

${ }^{20}$ Várias pesquisas nessa direção foram desenvolvidas pelo Grupo de Pesquisa em Educação, Linguagem e Práticas Culturais (Phala), as quais podem ser acessadas no site do grupo: (https://www.phala.fe.unicamp.br/).
} 
Na direção desta virada vital-praxiológica, segue-se, a título de exemplo, um modo possível de se problematizar uma prática amazônica de garimpagem da qual participam seres humanos, os garimpeiros; artefatos tecnológicos, tais como bateias, picaretas, pás, máquinas movidas a combustíveis fósseis etc.; outros seres naturais como o mercúrio - um metal líquido extraído de fontes naturais à temperatura ambiente - e ouro, outro metal extraído de

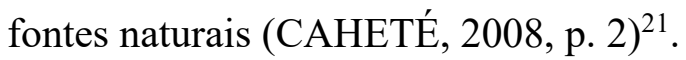

Uma prática de garimpagem pode ser realizada em um rio, na superfície terra ou em camadas profundas da terra. Quando realizada em um rio profundo como o Amazonas (Figura 2), ela se processa por meio do bombeamento do material do fundo do rio.

Figura 2 - Balsas de garimpagem no rio Amazonas.

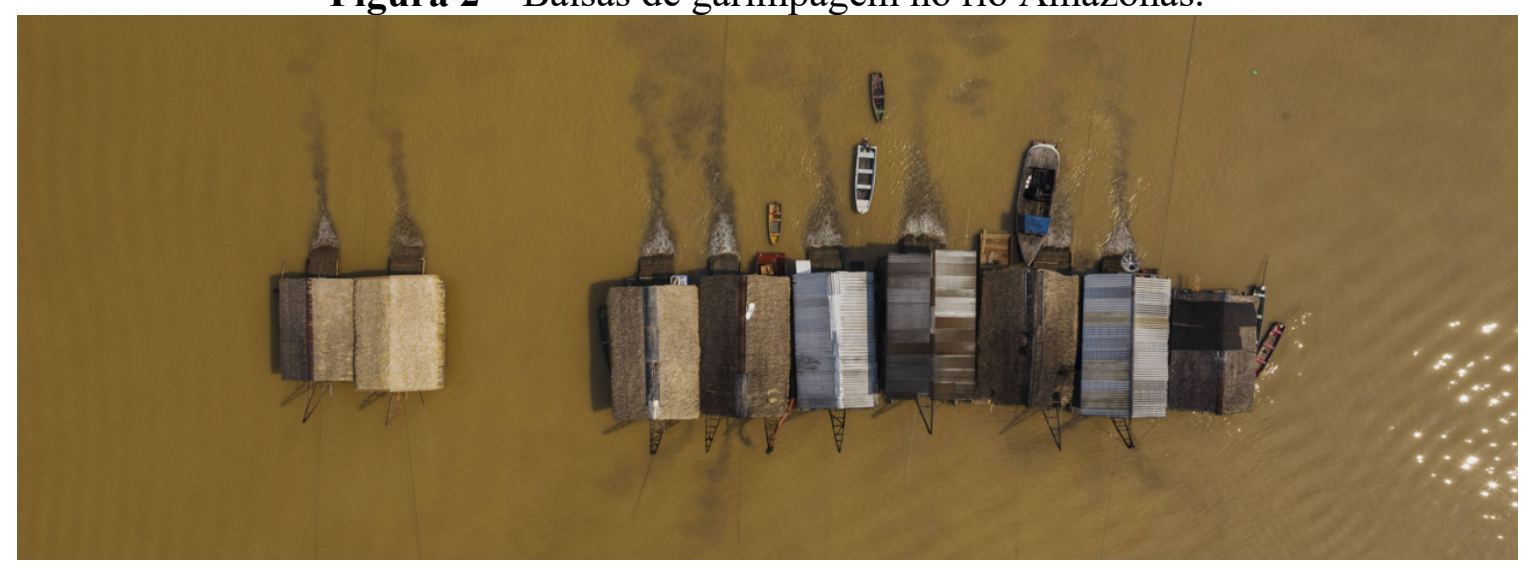

Fonte: https://www1.folha.uol.com.br/ambiente/2020/09/na-terra-de-mourao-garimpo-ilegal-opera-no-amsob-vista-grossa-do-exercito.shtml

O bombeamento para a superfície é feito em grandes balsas (Figura 3), em uma profundidade que varia de 15 a 50 metros. Os garimpeiros devem seguir certas regras para obterem ouro bruto. Esta prática se inicia na prospecção dos sedimentos do rio mediante o uso de uma sonda para identificação da região e da profundidade em que será desenvolvida a extração de ouro. Nesta etapa, já se manifesta a necessidade de identificação, controle e delimitação do espaço de modo a se atingir o propósito da garimpagem.

\footnotetext{
${ }^{21}$ Atualmente, prevalece nesta prática uma atividade totalmente mecanizada e industrial, envolvendo máquinas que chegam a custar 1 milhão de reais e vários trabalhadores em torno dela. Além disso, para a detecção de ouro, grandes empresas exploradoras têm usado o cianeto de sódio para explodir as áreas em superfícies abertas. Para mais detalhes, remetemos o leitor para o site: (https://www.nationalgeographicbrasil.com/meio-ambiente/2021/03/por-dentro-da-capital-do-garimpoouro-ilegal-da-amazonia).
} 
As dragas presentes nas balsas geralmente começam a operar à noite, para se evitar a fiscalização dos órgãos ambientais. É quando se ligam os potentes motores de dragagem dragas flutuantes ${ }^{22}$-, com bombas de sucção de 10 a 12 polegadas que possuem comandos hidráulicos de 165 CV cada um (CAHETÉ, 2008).

Figura 3 - Balsas usadas na prática da garimpagem

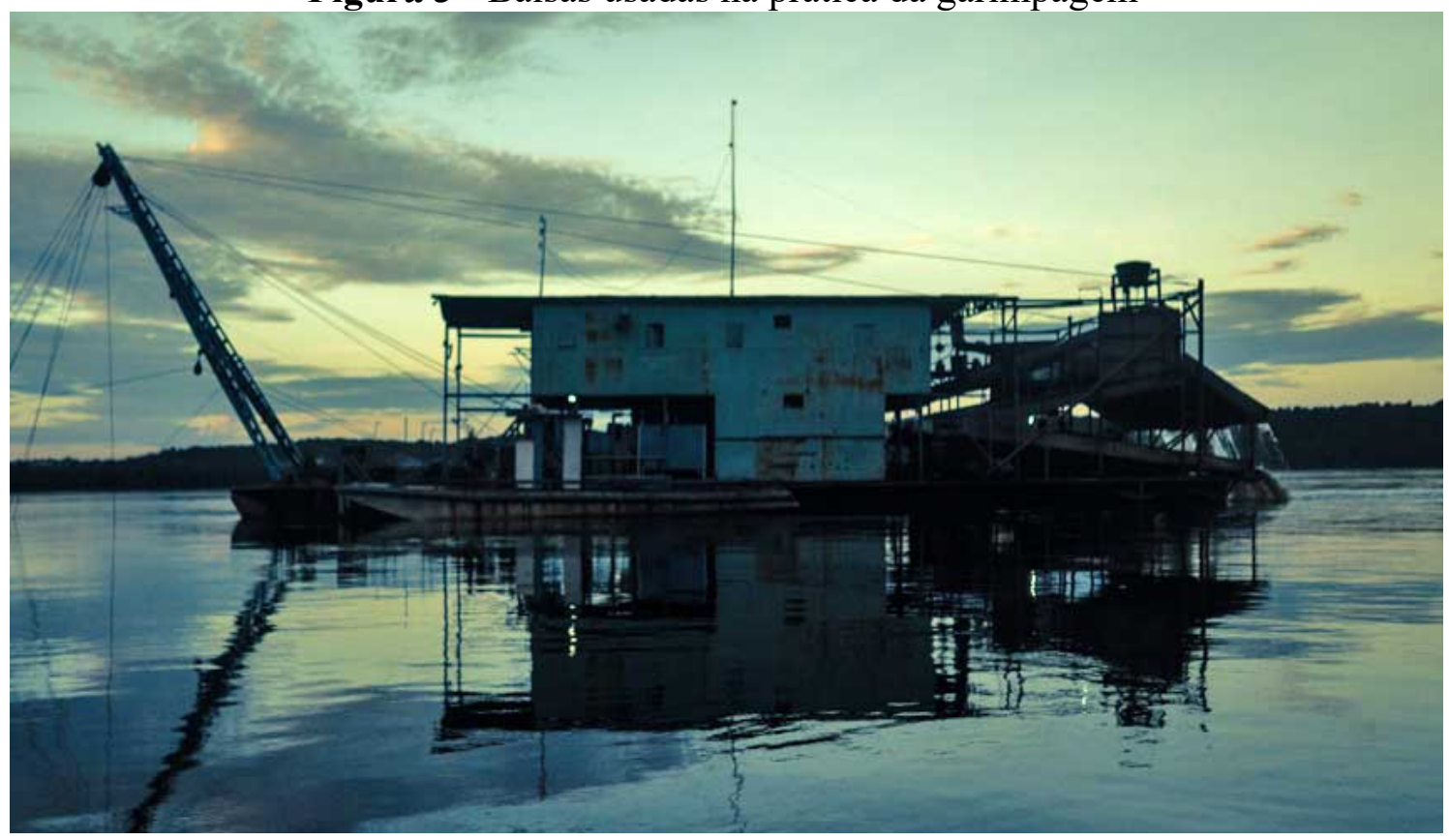

Fonte: Fotografia de Fabio Nascimento (2020). Disponível em: https://brasil.mongabay.com/2020/07/pordentro-do-garimpo-ilegal-de-ouro-na-amazonia/

Os motores de dragagem funcionam como se fossem furadeiras que perfuram e atritam o fundo dos rios, por meio de uma peça denominada "maraca"23. As mangueiras das dragas passam a sugar sedimentos do fundo do rio e a lançar toda a água sugada para uma espécie de cascata artificial. A água desta cascata é jogada sob tapetes grossos, com vistas a neles reter a areia e o ouro (Figura 4). Os demais sedimentos são reconduzidos para os leitos do rio.

22 "Uma draga é como um animal com duas trombas gigantes que submergem com guindastes nas profundezas do rio, buscando faíscas do metal precioso em meio a lodo, areia e pedras" (FALEIROS, 2020).

${ }^{23}$ Descrição de um garimpeiro em reportagem sobre a busca de ouro em rios amazônicos. Fonte: (https://www.youtube.com/watch?v=BUuqs6wWgFk\&t=11s).

Revista de Educação Matemática (REMat), São Paulo (SP), v. 19, Edição Especial, pp. 1-22, e022004, 2022, eISSN: 2526-9062 
Figura 4 - À esquerda, cascata artificial formada pelos sedimentos pesados extraídos do rio. À direita tapetes grossos que retêm areia e ouro.

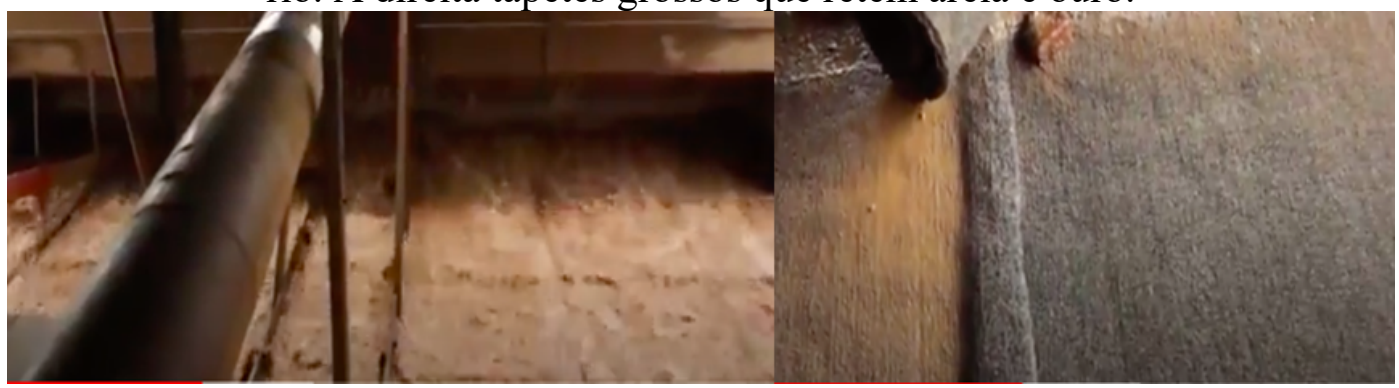

Fonte: https://www.youtube.com/watch?v=BUuqs6wWgFk\&t=11s

Após isso, os tapetes são lavados por jatos de água limpa corrente em uma grande mesa, onde novamente se usam tapetes, mas agora em dimensões menores com vistas a reter as partículas de ouro e areia que ficaram presas aos primeiros tapetes do processo inicial. Posteriormente, esses tapetes menores são lavados e batidos em um tanque de água limpa. Os garimpeiros aguardam a sedimentação do material arenoso (Figura 5) no fundo do tanque, para separar a água do referido material.

Figura 5 - Tanque de separação do material arenoso da água.

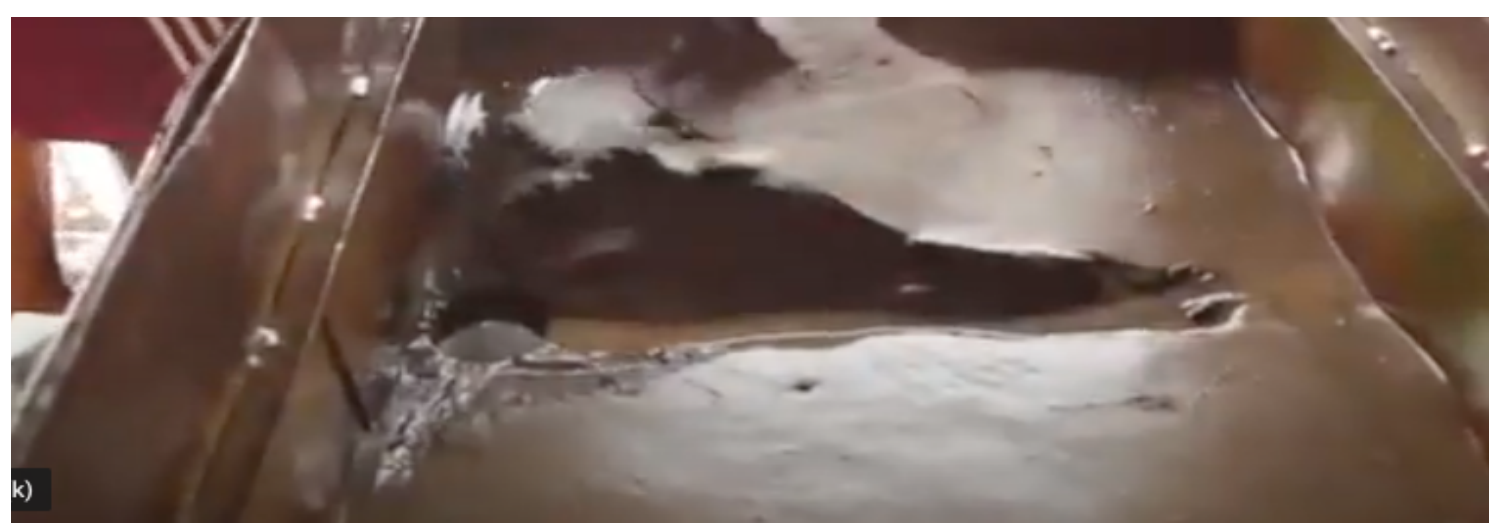

Fonte: https://www.youtube.com/watch?v=BUuqs6wWgFk\&t=11s

A próxima etapa da prática consiste em misturar o material arenoso com água limpa novamente; todavia, isso é realizado em baldes menores. Todo o material presente nesses baldes é retirado em pequenas quantidades, momento em que se acrescenta mercúrio a cada retirada, a fim de que ocorra a amalgamação do ouro. O mercúrio tem a capacidade de se unir ao ouro (bem como a outros metais), possibilitando a sua captação pela rápida agregação de suas partículas ao mercúrio. Os amálgamas encontrados são separados e a água utilizada 
na mistura é lançada de volta aos rios. Na sequência, os garimpeiros buscam a obtenção do ouro bruto, pelo processo de queima do amálgama ${ }^{24}$, pois, assim, o mercúrio volatiliza, evaporando-se em forma de gás para a atmosfera ${ }^{25}$ (Figuras 6, 7, 8). O ouro bruto passa então a ser pesado para fins de comercialização ${ }^{26}$.

Figuras 6 e 7 - Processo de aderência ao mercúrio à esquerda e a volatização do mercúrio à direita.
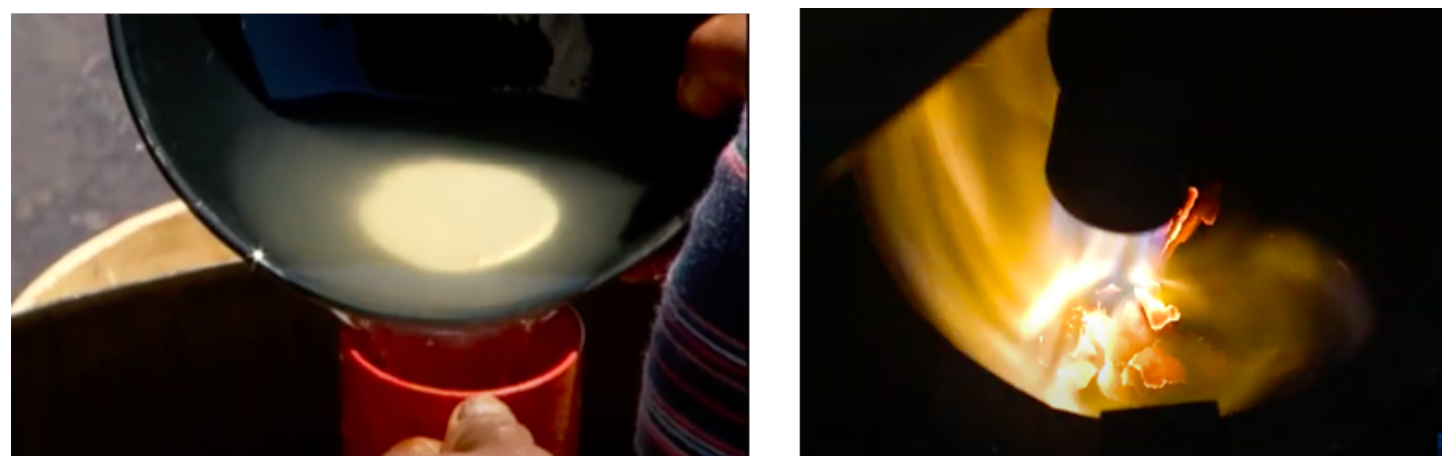

Fonte: https://www.youtube.com/watch?v=wQRQJdL0sQg

Figura 8 - Ouro na vasilha.

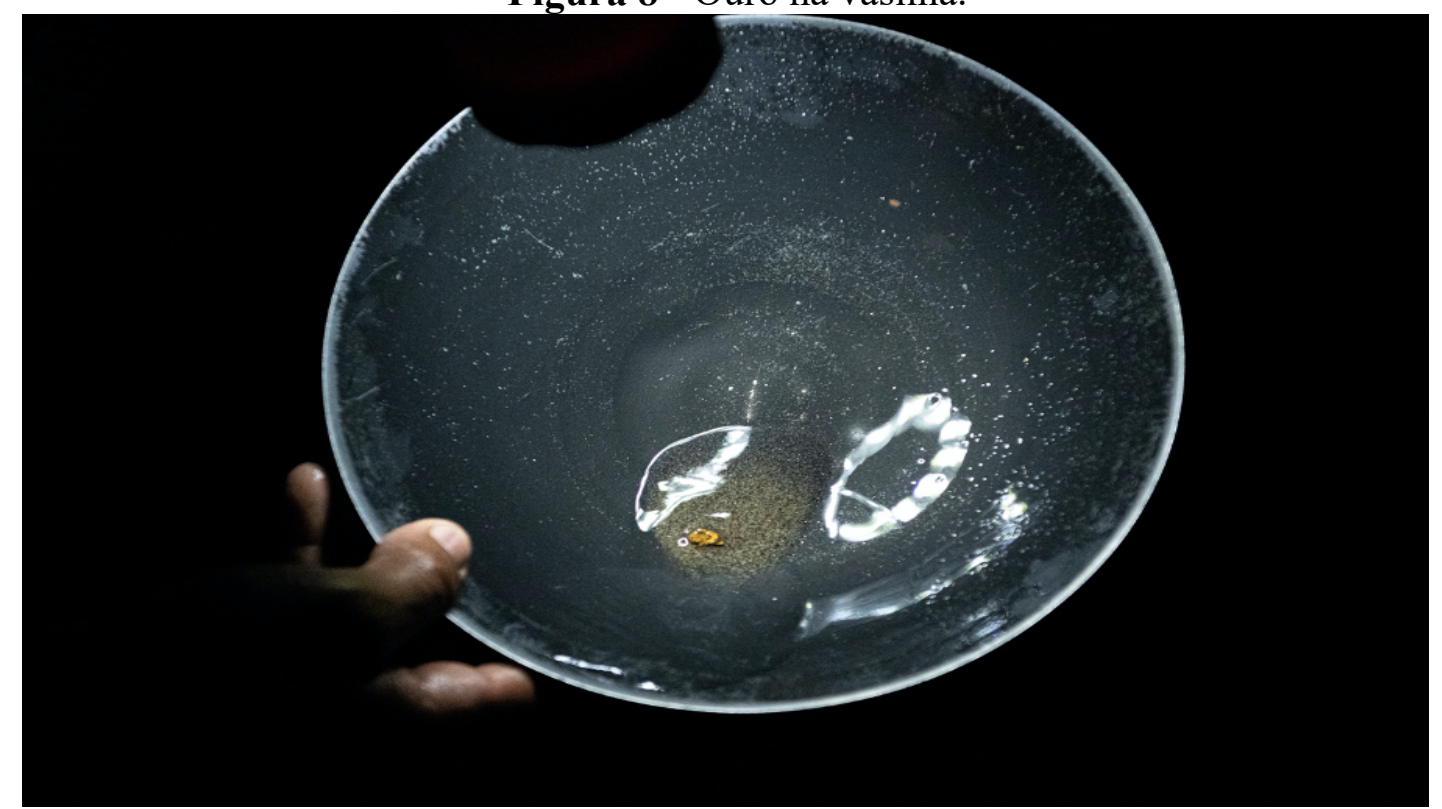

Fonte: Fotografia (2020) de Fabio Nascimento. Disponível em: https://brasil.mongabay.com/2020/07/pordentro-do-garimpo-ilegal-de-ouro-na-amazonia/

\footnotetext{
${ }^{24}$ Video: (https://www.oeco.org.br/reportagens/26988-porque-o-mercurio-e-usado-na-mineracao-de-ouro/).

${ }^{25}$ (SCARPELLI, 2003, apud DE-PAULA; LAMAS-CORREAA; TUTUNJI, 2006).

${ }^{26}$ A comercialização legal do ouro envolve a autodeclaração da sua procedência na documentação de Contribuição Financeira por Exploração Minerária (CFEM). Todavia, em função da precariedade documental para esse registro, estimase que a maioria do ouro comercializado, inclusive na bolsa de valores, seja ouro retirado em Lavras sem registro.
}

Revista de Educação Matemática (REMat), São Paulo (SP), v. 19, Edição Especial, pp. 1-22, e022004, 2022, eISSN: 2526-9062 
No contexto de formação indisciplinar de educadores, a descrição dessa prática amazônica da garimpagem possibilita dar visibilidade e esclarecimento da concepção vitalpraxiológica das matemáticaS que estamos aqui apresentando. Dado que a detecção e extração de ouro constitui o propósito comunitário que orienta as interações dos participantes humanos e não humanos (garimpeiros, máquinas, água, mercúrio, ouro, dragas, o espaço marítimo etc.) nos jogos de linguagem que se desenvolvem nessa prática, tal propósito se diz "normativo" justamente porque existem procedimentos regrados, mecânicos e sequenciados que, se seguidos à risca pelos participantes, contemplam o propósito dessa prática: detectar ou não uma fonte de ouro e, em caso positivo, extraí-lo. É a existência de tal normatividade que, sob a perspectiva de Turing, torna o garimpo do ouro um problema matemático decidível e, sob a perspectiva wittgensteiniana ${ }^{27}$, um jogo de linguagem normativo ou matemático. Tal jogo de garimpagem é normativo e decidível, independentemente do fato dos garimpeiros detectarem ou não ouro, bem como de, em caso positivo, não terem conseguido extraí-lo, por quaisquer razões que poderiam ser identificadas e corrigidas.

A investigação da rede complexa de efeitos gerados por tal prática sobre diferentes formas de vida possibilita também problematizar os aspectos ambientais, políticos, jurídicos, tecnológicos, trabalhistas, éticos, étnicos, estéticos etc. vinculados à sua realização e, particularmente, o aspecto relativo à contaminação dos humanos e de outros seres naturais pelo uso do mercúrio ${ }^{28}$, de combustíveis fósseis etc. É a problematização vital-praxiológica dos efeitos e dos afetos de tal prática sobre as vidas dos seres naturais - humanos ou não humanos -, bem como sobre as suas formas de produzirem, reproduzirem ou extinguirem vidas e formas de vida na Terra que constitui o propósito político-pedagógico decolonial das práticas de garimpagem.

Destacando-se alguns desses efeitos, constata-se, atualmente, que na Amazônia, a terra indígena mais afetada por práticas de garimpagem é a da etnia Munduruku, onde há mais de 600 registros de garimpo legalizados ou com pedido de autorização de lavra na Agência Nacional de Mineração. "Em três comunidades Munduruku, 6 em cada 10 indígenas

\footnotetext{
27“"É o uso que se faz fora da matemática e, portanto, os significados dos signos, aquilo que transforma em matemática o jogo de signos" (WITTGENSTEIN, 2017, Parte V-\$2).

${ }^{28}$ Fonte:(https://ciclovivo.com.br/planeta/meio-ambiente/plataforma-reune-dados-sobre-mercurio-e-garimpo-naamazonia/).
} 
apresentaram níveis de mercúrio acima dos limites máximos estabelecidos como seguros por agências de saúde internacionais"29 (Figura 9). Com isso, a exploração ilegal e legal de garimpos tem gerado violentos conflitos entre os indígenas Yanomamis e os garimpeiros não indígenas, bem como entre os próprios indígenas.

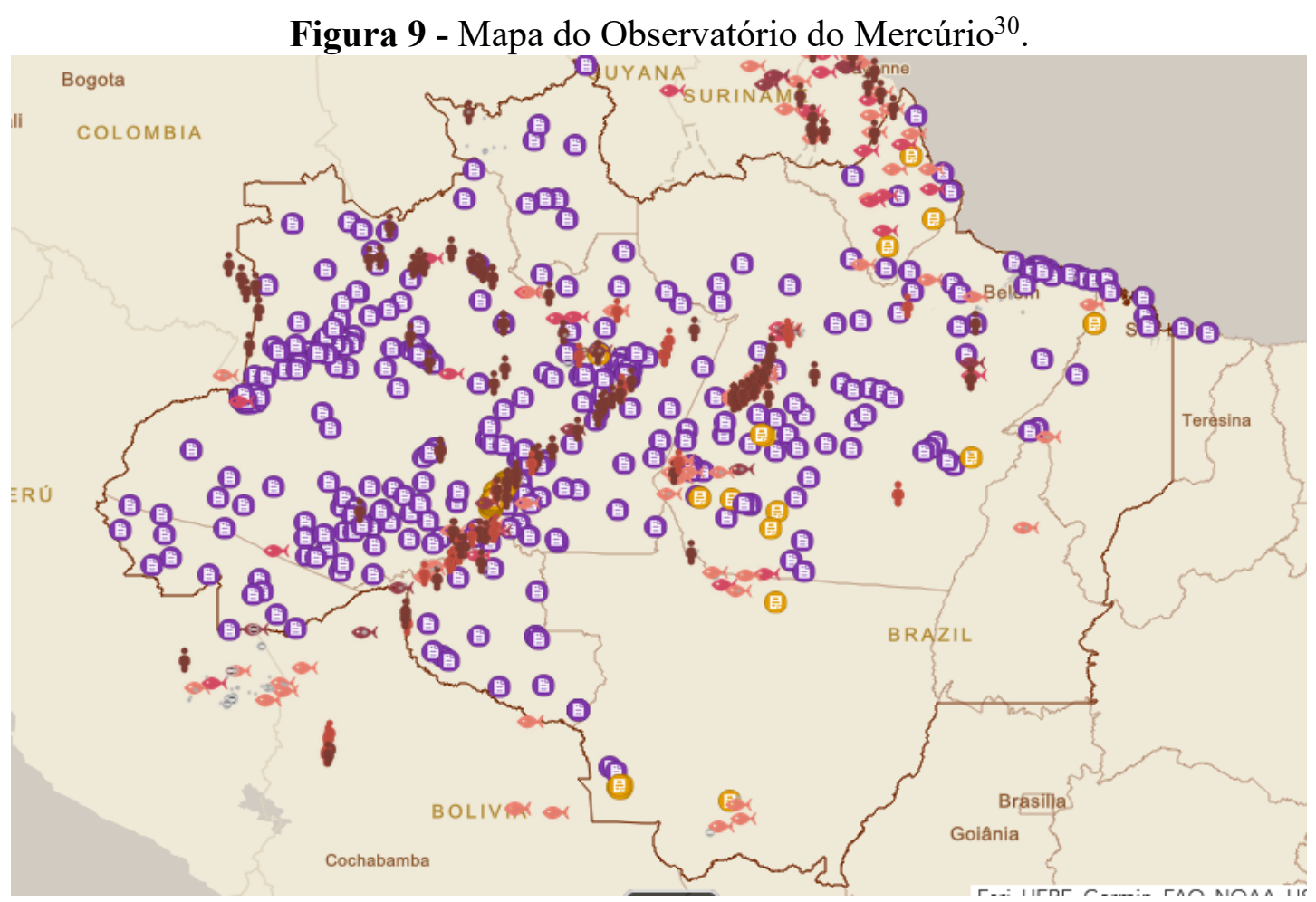

Fonte: Observatório do Mercúrio na Amazônia.

Com a legenda dos peixes, que indica os rios que apresentam maior ou menor contaminação por mercúrio, este mapa georreferenciado da Amazônia brasileira (Figura 9) dá visibilidade às práticas predatórias realizadas por humanos sobre os demais seres naturais. A legenda de pessoas corresponde às regiões e povos contaminados por mercúrio; já as bolinhas roxas representam as ações do Ministério Público relacionadas aos garimpos, mostrando as terras Munduruku, no Pará, a área dos Menkragnotí; a Terra Indígena Baú, do povo Kayapó; e a Terra Indígena Xikrin do Cateté, regiões de grande conflito e degradação

\footnotetext{
${ }^{29}$ Fonte: (http://informe.ensp.fiocruz.br/noticias/51819).

${ }^{30}$ O Observatório do Mercúrio na Amazônia - plataforma lançada em 20 julho de 2021 pelo WWF-Brasil, em parceria com Fiocruz, CINCIA e outras instituições - onde se reúnem resultados de estudos e informações sobre contaminação com mercúrio de humanos e não humanos na região Pan-Amazônica.

(https://panda.maps.arcgis.com/apps/webappviewer/index.html?id=e6717bfa09504157b187e076f79e1d0e\&extent=$12634275.965 \% 2 \mathrm{C}-3100771.0732 \% 2 \mathrm{C}-3960813.4914 \% 2 \mathrm{C} 1849902.3748 \% 2 \mathrm{C} 102100)$.
}

Revista de Educação Matemática (REMat), São Paulo (SP), v. 19, Edição Especial, pp. 1-22, e022004, 2022, eISSN: 2526-9062 
ambiental. No Maranhão, há garimpo no limite da terra indígena Alto Turiaçu; no Amazonas, nas Terras Indígenas Marapi, Rio Biá, Waimiri-Atroari, dentre outras.

Quando pensamos a formação de educadores sob um viés vital-praxiológico, a dicotomia homem-natureza ${ }^{31}$ é desconstruída, passando-se a promover um projeto político bioeticologicamente vicejável. As práticas culturais e as vidas, tais como se realizam e se constituem em diferentes formas de vida, passam a ser vistas como o eixo da ação educativa e da formação de educadores. Com isso, novos modos de se ver as relações e implicações mútuas que se estabelecem entre humanos e demais seres naturais - vistos como a condição inalienável de produção e reprodução das vidas em todas as formas de vida - passam a ser problematizados. Sob a perspectiva de uma virada vital-praxiológica, problematizar tais relações de forma transgressiva e indisciplinar constitui o núcleo político da formação de estudantes e educadores (SOUZA, MIGUEL, 2020). Embora tais relações de colaboração e negociação mútuas entre humanos e não humanos na produção e reprodução de vida na Terra sejam necessárias, elas passaram a ser vistas, desde o advento do empreendimento colonizador-civilizatório europeu moderno como relações bélico-imperialistas, em que humanos passaram a confrontar predatória e agonisticamente os demais seres naturais até o limite de seu esgotamento e extinção.

Assim, a virada vital-praxiológica na formação de educadores que aqui propomos nos convida a ver de um modo decolonial e indisciplinar tais políticas de formação, e a colocar as práticas culturais como o seu alvo privilegiado, dado serem elas, o solo áspero produtor e reprodutor de todas as vidas e formas de vida no planeta. Esta virada nos convida, enfim, a desconstruirmos a pureza cristalina do ouro do cetro mágico através do qual a "rainha das ciências" insiste em eliminar dos nossos caminhos as impurezas do solo áspero do qual brotam e vicejam as vidas em todas as formas de vida. Queremos caminhar! Voltemos, pois, ao solo áspero!

\footnotetext{
31"O uso das categorias "natural" e "natureza" é fundamental para a empresa moderna-colonial-capitalista-global. "Natureza" tem um duplo sentido. Por um lado, o ser humano racional, isto é, o homem europeu, possui a superioridade intelectual que lhe autoriza o domínio do âmbito natural, seja ele representado pelas mulheres europeias, naturalmente inferiores aos homens europeus, seja representado pelas comunidades e sociedades não europeias. Classificar algo como "natural" equivale, nesse contexto histórico, a autorizar sua exploração" (CASTRO, 2020, p. 149).
} 


\section{REFERÊNCIAS}

CAHETÉ, F. S. A Extração do Ouro na Amazônia e Implicações para o meio ambiente.

Novos Cadernos NAEA, [S.1.], v. 1, n. 2, dez. 2008. Disponível em:

https://periodicos.ufpa.br/index.php/ncn/article/view/14

CHAVES, W. M. B. Urnas funerárias: Os Marajoaras e suas Representações Visuais.

Dissertação de Mestrado. Instituto de Artes. UNB. 2020.

CASTRO, S. Condescendência: estratégia pater-colonial de poder. In: HOLLANDA, Heloísa Buarque de (org.). Pensamento Feminista Hoje: Perspectivas decoloniais. Rio de Janeiro: Bazar do Tempo, 2020. Disponivél em:

https://revistas.ufpi.br/index.php/fundamentos/article/view/7863

DE-PAULA, V. G.; LAMAS-CORRÊA, R.; TUTUNJI, V. L. Garimpo e mercúrio: impactos ambientais e saúde humana. Em Universitas: Ciências da Saúde, v. 4, n. 1 / 2 , p. 101-110, 2006. Disponível em:

https://www.publicacoesacademicas.uniceub.br/cienciasaude/article/view/25

FALEIROS, G. Por dentro do garimpo ilegal de ouro na Amazônia. Em Jornal Mongabay, 2020. Disponível em: https://brasil.mongabay.com/2020/07/por-dentro-dogarimpo-ilegal-de-ouro-na-amazonia/

HADDOCK-LOBO, R. Considerações sobre "Posições" de Derrida. Em o que nos faz pensar no. 21, maio de 2007. Disponível em: http://www.oquenosfazpensar.fil.pucrio.br/index.php/oqnfp/article/view/219/218

MIGUEL, A.; TAMAYO, C. Wittgenstein, Terapia e Educação Escolar Decolonial. Em Educação e Realidade, v. 45, n. 3, 2020. Disponível em: https://www.scielo.br/j/edreal/a/Dr9NNdnXMHChBfYvVRdXrVf/?lang=pt

PAHL SCHAAN, D. A arte da cerâmica Marajoara: Encontros entre o passado e o presente. Em revista Habitus, v. 5, n.1, p. 99-117, jan.jun. 2007. Disponível em: http://seer.pucgoias.edu.br/index.php/habitus/article/view/380/316

SOUZA, E. G.; MIGUEL, A. A encenação de práticas culturais na tessitura de outras escolas: a vida como eixo da ação educativa. REMATEC: Revista de Matemática, Ensino e Cultura, v. 15, n. 33, p. 166-184, 2020. Disponível em: http://www.rematec.net.br/index.php/rematec/article/view/227

TURING, A. M. On computable numbers, with an application to the entscheidungsproblem. The Graduate College, Princeton University, New Jersey, U.S.A., p. 230-265, 1936.

WALSH, C. Interculturalidad crítica y educación intercultural. 2009. Palestra apresentada no Seminario "Interculturalidad y Educación Intercultural". Instituto Internacional de Integración del Convenio Andrés Bello, La Paz.

Revista de Educação Matemática (REMat), São Paulo (SP), v. 19, Edição Especial, pp. 1-22, e022004, 2022, 
WITTGENSTEIN, L. Philosophische Untersuchungen/Investigações filosóficas. Trad. de ALMEIDA, J.J. Edição Bilíngue Alemão-Português, 2017. 